• 研究报告・

\title{
古田山常绿阔叶林不同演替群落的萌生特征
}

池秀莲 ${ }^{1}$ 王庆刚 ${ }^{2}$ 郭 强 ${ }^{3}$ 杨 弦 ${ }^{3}$ 唐志尧 ${ }^{3}$

1 (中国中医科学院中药资源中心, 道地药材国家重点实验室培育基地, 北京 100700)

2 (中国农业大学资源与环境学院生态科学与工程系, 生物多样性与有机农业北京市重点实验室, 北京 100193)

3 (北京大学城市与环境学院生态学系, 北京大学地表过程分析与模拟教育部重点实验室, 北京 100871)

摘要: 萌生是植物营养繁殖的重要方式之一, 树木的萌生更新对群落结构的维持、植被的动态和演替具有重要意 义。本研究基于古田山常绿阔叶林内处于不同演替阶段的 25 个 $30 \mathrm{~m} \times 30 \mathrm{~m}$ 样方中胸径 $\geq 5 \mathrm{~cm}$ 的木本植物萌生茎 发生情况的调查数据, 应用线性回归模型分析了不同演替群落的萌生特征及其地形解释。结果发现: (1)样地内共 有 56 种木本植物存在萌生现象, 占总物种数的 $53.8 \%$ 。(2)群落(样方)水平的萌生能力与海拔显著负相关, 与坡度和 坡向的相关性较弱。(3)群落水平的萌生能力与林分年龄显著负相关; 在控制地形因子的影响下, 林分年龄对萌生 指标解释量仍然达到 $20 \%-30 \%$ 。萌生个体数和萌生物种丰富度所占比例随林分年龄显著下降, 萌生物种主茎的平 均胸径随林分年龄显著增加。研究表明, 古田山常绿榈叶林萌生能力随林分年龄的增大而下降, 可能由演替序列 上物种组成的变化(即萌生能力较强物种的多度下降)和群落结构的变化(即大径级个体增多)导致。另外, 萌生能力 受到海拔、坡向等地形因素的影响。

关键词: 森林更新; 萌生茎; 林分年龄; 地形

\section{Sprouting characteristics of communities during succession in an ever- green broad-leaved forest on Gutian Mountain, East China}

\author{
Xiulian $\mathrm{Chi}^{1}$, Qinggang Wang ${ }^{2 *}$, Qiang Guo ${ }^{3}$, Xian Yang ${ }^{3}$, Zhiyao Tang ${ }^{3}$ \\ 1 National Resource Center for Chinese Materia Medica, China Academy of Chinese Medical Sciences, State Key \\ Laboratory Breeding Base of Dao-di Herbs, Beijing 100700 \\ 2 Department of Ecology and Ecological Engineering, College of Resources and Environmental Sciences, and Key \\ Laboratory of Biodiversity and Organic Farming of Beijing City, China Agricultural University, Beijing 100193 \\ 3 Department of Ecology, College of Urban and Environmental Sciences, The Key Laboratory for Earth Surface \\ Processes of the Ministry of Education, Peking University, Beijing 100871
}

\begin{abstract}
Sprouting is an important vegetative reproduction strategy. Sprouting in woody plants is especially of great significance for maintaining forest structure and influencing vegetation dynamics and succession. In this study, we collected sprout data from 25 plots $(30 \mathrm{~m} \times 30 \mathrm{~m})$ in an evergreen broad-leaved forest on Gutian Mountain, Zhejiang Province, East China for all trees with diameter at breast height (DBH) equal to or greater than $5 \mathrm{~cm}$. Based on this data, we used general linear regression models to explore the characteristics and the effects of topographic factors and forest age on sprouting ability in forest communities during succession. We found that (1) 53.8\% (56/104) of species in this forest showed evidence of sprouting. (2) The plot-level sprouting ability decreased significantly with elevation and marginally decreased significantly with aspect. (3) The plot-level sprouting ability decreased significantly with forest age. Forest age explained $20 \%-30 \%$ of the variation in sprouting ability after being fitted with the models using topographical factors. Both the number of sprouting genets and the proportion of sprouted species richness decreased significantly, while the mean DBH of sprouting genets increased significantly with forest age. This study shows that a decrease in community sprouting ability coupled with an increase in forest age may result from changes in both species composition (i.e. a decreasing number of individuals, but a higher sprouting ability) and structure (i.e. an increasing in proportion of larger individuals) during forest succession. In
\end{abstract}


addition, the sprouting ability of forest communities is also affected by topographical factors, such as elevation and aspect.

Key words: forest regeneration; sprouts; forest age; topography

萌生是植物适应干扰胁迫的重要更新策略 (Bond \& Midgley, 2001; Del Tredici, 2001)。与实生 策略依赖于种子进行有性繁殖不同, 萌生是在根 颈、树干基部的木质瘤、根部等产生萌生枝苗, 从 而形成多茎干植株(Bellingham \& Sparrow, 2000; 闵 恩荣等, 2005)。许多木本植物在受到干扰后, 通过 萌生补充新的枝干, 从而持续占据原有生态位, 完 成原位更新。因此, 植物的萌生对物种周转, 植被 的演替、恢复和保护有重要的意义(Bond \& Midgley, 2001, 2003; Wang et al, 2007; Clarke et al, 2010)。然 而, 以往研究多从种子雨、种子库、幼苗动态等方 面关注植物实生更新及其对多样性维持的重要意 义, 关于萌生更新策略及其在群落结构和动态中的 作用研究仍不足(Wang et al, 2007; Shen et al, 2011)。

目前有关植物萌生的研究多集中于火干扰或 干旱胁迫较严重的区域(Paula \& Pausas, 2006; Paula et al, 2006, 2009)。例如, Verdú (2000)在地中海地区 发现, 以实生更新为主的物种其果实类型通常为干 果, 种子小而轻, 适合于风媒传播, 并且具有较快 的生长速率; 而以萌生更新为主的物种则多具肉果, 种子大而重, 且多为硬叶植物, 生长速率较慢。表 明具有不同更新策略的物种, 能够通过改变其生活 史策略, 适应局域环境并达到稳定共存。国内学者 也针对我国温带和亚热带森林内萌生策略的重要 性开展了一系列研究(如Wang et al, 2007; Ye et al, 2014; 叶铎等, 2017, 2018)。其中 Wang等(2007)在浙 江天童山的研究发现, 萌生对该地区受损常绿阔叶 林的更新和恢复发挥了重要作用。尽管萌生策略作 为群落内植物更新的重要方式, 被广泛地认为能够 显著影响群落组成及动态变化, 但以往多数研究仅 关注某一特定演替阶段的群落, 忽略了萌生策略在 不同演替阶段的相对重要性(胡正华和于明坚, 2006; 陈沐等, 2007; 苏建荣等, 2012)。

当干扰强度较低、种间竞争关系稳定时, 物种 更倾向于采取实生更新的策略(陈沐等, 2007)。而在 经过干扰(如砍伐、火烧、台风、泥石流等)后的森 林恢复和演替过程中, 萌生更新的作用可能会发生
变化(Kammesheidt, 1998; Shen et al, 2011; 苏建荣 等, 2012)。由于萌生更新具有抗干扰能力强、幼年 期生长迅速等优点, 群落演替前期时萌生植株通常 较多, 对群落树种多样性的维持发挥了重要作用; 到了演替中期, 萌生个体开始进入种子繁殖阶段, 实生更新植株逐渐增多, 萌生更新逐渐弱化。随着 演替的进行, 群落整体萌生能力变化的原因可以概 括为两类: 第一, 树木的萌生能力与其母树所处的 生长发育阶段密切相关, 大多数植物在幼树期的萌 生能力较强, 成年后的萌生能力会有所下降或丧失 (Kammesheidt, 1998; Pausas, 2001; 刘常幸等, 2014)。随着演替的进行, 大径级树木的个体比例会 增加, 从而导致整体萌生能力下降。第二, 随着演 替的进行, 物种组成和结构会发生变化, 可能会造 成某些萌生能力强的物种多度下降甚至消失, 从而 造成群落整体萌生能力下降。在我国湿润气候区开 展植物萌生能力随演替阶段变化的研究, 并厘清其 可能的原因, 将对我国热带和亚热带森林资源管理 和保护具有一定的指导意义。

我国热带和亚热带森林多分布于地形复杂多 变的山区, 有研究表明地形对植物萌生格局有显著 影响(如刘海波等, 2014; Ye et al, 2014; 郭屹立等, 2015)。在以空间代替时间的群落演替平台开展研究 时, 有必要考虑地形引起的生境异质性对萌生格局 的潜在影响。为此, 本研究将基于古田山常绿阔叶 林内处于不同演替阶段的 25 个 $30 \mathrm{~m} \times 30 \mathrm{~m}$ 样方中 胸径 $\geq 5 \mathrm{~cm}$ 的木本植物萌生更新发生情况的调查数 据, 分析揭示该地区常绿阔叶林不同演替群落的萌 生特征, 并考虑地形的影响, 以期从萌生更新的角 度深化对常绿阔叶林群落演替过程中植物相关更 新机制的理解。

\section{研究方法}

\section{1 研究区概况}

研究区位于浙江省开化县古田山国家级自然保 护区 $\left(29^{\circ} 8^{\prime} 18^{\prime \prime}-29^{\circ} 17^{\prime} 29^{\prime \prime} \mathrm{N}, 118^{\circ} 03^{\prime} 49^{\prime \prime}-118^{\circ} 11^{\prime} 12^{\prime \prime} \mathrm{E}\right)$, 总面积为 $8,107 \mathrm{ha}$ 。该区域的年均温为 $15.3^{\circ} \mathrm{C}$, 年降 
水量为 $1,963.7 \mathrm{~mm}$ (胡正华和于明坚, 2006)。该地区 地带性植被类型为亚热带常绿阔叶林, 但现有植被 主要由伐木迹地恢复演替形成，因恢复时间不同形 成不同的演替群落(Bruelheide et al, 2011)。处于演 替前期的群落优势物种多为马尾松 (Pinus massoniana)和短柄枹栋(Quercus serrata)等, 演替后期的 群落优势物种则多为甜槠(Castanopsis eyrei)和木荷 (Schima superba)等(Lang et al, 2012)。

\section{2 样方设置}

2008年, 为深入探讨生物多样性与生态系统功 能的关系, “中国亚热带森林生物多样性与生态系 统功能试验研究项目 (Biodiversity-Ecosystem Functioning China project, 简称BEF-China)”在古田 山国家级自然保护区开展(Bruelheide et al, 2011)。 BEF-China研究组在整个保护区范围内布设了 27 个 面积大小为 $30 \mathrm{~m} \times 30 \mathrm{~m}$ 的样方。根据各样方的历史 砍伐活动记录将其划分为 5 个演替阶段, 每个演替 阶段包括的样方重复数分别为 $5 、 4 、 5 、 6 、 7$ 个, 对 应样方的平均林龄大致为 $<20$ 年、20-39年、40-59 年、60-79年、 $\geq 80$ 年。

\section{3 萌生更新调查}

2010年9月, 研究组成员对样方内胸径 $\geq 5 \mathrm{~cm}$ 的所有树木个体及其基部萌生茎干(以下称“萌茎”) 进行了复查, 主要测量并记录了所有个体及萌茎的 胸径、树高、空间位置以及生活状态等。本研究参 照已有研究报道, 以多茎干(multi-stemmed)的萌生 现象来代表萌生更新(Del Tredici，2001; 叶铎等, 2017)。考虑在实际调查过程中无法对植株根部进行 挖掘观测, 本研究将多茎干植株中胸径最大的记录 为主茎, 其他从主茎基部生出且与主茎物种相同的 较小的萌生植株均视为萌茎。复查发现其中 2 个样 方(均处于第一演替阶段)内所有胸径 $10 \mathrm{~cm}$ 及以上 的植株均被砍伐, 原有群落结构破坏殆尽, 所以本 研究仅选用了剩余的 25 个样方的调查数据。

\section{4 萌生能力指标计算}

萌茎数量是表征萌生能力强弱的常用指标。 $5 \mathrm{~cm}$ 是一般林业调查的起测胸径, 胸径 $5 \mathrm{~cm}$ 以上萌 茎比小径级的萌茎具有较高的存活率, 是森林结构 和生物量的主要贡献者, 比较能反映群落发展趋 势。因此, 本研究只统计群落内胸径 $\geq 5 \mathrm{~cm}$ 的存活 萌茎数量来表征其萌生能力。

本研究采用萌生率 (ratio of the number of sprouts to the number of main stems, RS)、萌生个体 比例(proportion of sprouting individuals among all individuals, PMSI) 以及萌生个体平均萌茎数(number of sprouts per sprouting individual, NSMSI) 3 个指标 表征物种和群落(样方)水平的萌生能力(Nanami et al, 2004), 具体公式如下:

萌生率 $(\mathrm{RS})=$ 某一物种(或样方)的萌茎数/该 物种(或样方)所有个体数

萌生个体比例 $(\mathrm{PMSI})=$ 某一物种(或样方)的 萌生个体数/该物种(或样方)所有个体数

萌生个体平均萌茎数 $(\mathrm{NSMSI})=$ 某一物种 $($ 或 样方)的萌茎数/该物种(或样方)的萌生个体数 其中, RS = PMSI × NSMSI。NSMSI越大，表示萌生 能力越强; PMSI越大，表示萌生现象越普遍 (Nanami et al, 2004; 周赛霞等, 2011)。RS是反映萌 生特征的综合指标，其值越大，可能是萌生现象普 遍及萌生能力强的共同结果, 也可能是其中一方面 绝对优势的结果(Nanami et al, 2004)。

\section{5 林分年龄及地形因子的测定}

由于根据历史砍伐事件难以精确确定林分年 龄, BEF-China研究组进一步利用各样方胸径大小 位列第五的大树(简称“第五大树”)的胸径估测了林 分年龄(Bruelheide et al, 2011)。具体方法如下：首先 调查测量了各样方内所有胸径 $\geq 10 \mathrm{~cm}$ 树木的大小, 并随机钻取其中159株树木的树芯, 根据年轮定年 后，构建树龄和胸径的异速生长方程。然后将各样 方第五大树的胸径代入异速生长方程，估算得到树 龄，并以此树龄指代对应群落(样方)的具体年龄。这 一方法所得林分年龄与根据历史砍伐记录确定的 演替阶段具有很显著的相关关系 $(r=0.880, P<$ 0.001, Bruelheide et al, 2011)。本研究直接用估算的 林分年龄表征群落演替先后。

地形因子包括海拔、坡度和坡向。在每个样方 的中心位置用Garmin Geoko 201 GPS (Garmin, 美 国)测定海拔，选择样方内能代表样方平均坡度的 位置用地质罗盘仪测定坡度和坡向。测得 25 个样方 平均海拔为 $540 \mathrm{~m}(250-900 \mathrm{~m})$, 平均坡度为 $34^{\circ}$ $\left(14^{\circ}-47^{\circ}\right)$, 平均坡向为 $188^{\circ}\left(7^{\circ}-358^{\circ}\right)$ 。在分析过程 中, 将坡向按 $\mid$ 坡向度数 $-180 \mid \div 57$.3进行转化。通 过该公式计算以后，所有的坡向值位于 0 (朝 南)-3.14 (朝北)之间。 


\section{6 数据分析}

采用一元线性回归方法分析群落萌生能力指 标RS、PMSI、NSMSI与林分年龄、地形因子(海拔、 坡度及坡向)之间的关系。为了控制地形因素的影 响, 首先采用多元回归方法分析群落萌生能力与海 拔、坡度及坡向的关系，并获得模型的残差，然后 利用一元线性回归方法分析林分年龄与模型残差 的关系。

为了检验萌生能力随演替阶段变化是否与树 木生活阶段变化有关, 我们采用一元线性回归检验 了萌生物种主茎平均胸径与林分年龄的关系。为了 检验萌生能力随演替阶段的变化是否与树种组成 和结构变化有关，我们采用一元线性回归分别检验 了萌生物种丰富度、萌生物种丰富度占样方内所有 物种丰富度的比例、萌生物种个体数与林分年龄的 关系。

以上所有分析与作图均在R软件(R Core Team, 2016)中完成。

\section{结果}

\section{1 萌生特征}

样方调查共发现古田山常绿阔叶林内胸径 $\geq 5 \mathrm{~cm}$ 的木本植物 3,420 株, 隶属于 35 科 65 属 104 种, 其中 隶属于 23 科 40 属 56 种的 567 株树木具萌生现象, 萌 茎总数为 931 株。萌生物种的数量及其个体数分别 占所有木本植物物种总数及其个体总数的 $53.8 \%$ 和 $16.6 \%$ 。萌生物种的萌生能力差异较大, 萌生率(RS) 介于 $0.02-2.00$, 平均值为 $0.41 \pm 0.43$; 萌生个体比 例 $(\mathrm{PMSI})$ 介于 $0.02-1.00$, 平均值为 $0.29 \pm 0.28$; 萌 生个体平均萌茎数(NSMSI)介于 $1-4$, 平均值为 1.35 \pm 0.61 。其中, 甜槠、石栋(Lithocarpus glaber)和木 荷是古田山常绿阔叶林的重要组成树种, 其萌茎总 数均超过 100 株, NSMSI也均大于 1.5 , 萌生能力较 强(表1)。

每个样方的萌茎总数介于10-181株, 平均值为 $37.2 \pm 38.5$ 株; 样方(群落)的RS介于 $0.05-0.89$, 平 均值为 $0.27 \pm 0.23$; PMSI介于 $0.04-0.41$, 平均值为 $0.17 \pm 0.11$; NSMSI介于 $1.00-2.41$, 平均值为 $1.48 \pm$ 0.40 。

\section{2 萌生能力与地形因子的关系}

群落(样方)水平的RS与PMSI均随海拔升高呈 显著下降的趋势 $(P<0.05)$, 海拔对群落RS和PMSI
的解释量分别为 $25.8 \%$ 和 $26.2 \%$ (表2)。海拔与群落 NSMSI呈边缘显著负相关 $(P=0.0522)$, 海拔对群落 NSMSI的解释量为 $15.4 \%$ (表2)。坡度和坡向对群落 RS、PMSI、NSMSI的解释量在1.5\%-12.9\%, 且群 落RS、PMSI、NSMSI均随坡度和坡向(朝北)而下降 (表2); 但除了群落PMSI与坡向呈边缘显著 $(P=$ $0.0781)$ 外, 其余各项关系均不显著 $(P>0.10$, 表2)。

\section{3 萌生能力与林分年龄的关系}

群落(样方)水平的RS、PMSI、NSMSI均随林分 年龄的增加而呈显著的下降趋势 $(P<0.05)$ 。林分年 龄对群落RS、PMSI和NSMSI的解释量分别达到 $38.3 \%$ 、29.5\%和 $32.2 \%$ (表2，图1)。RS、PMSI和 NSMSI与地形因子回归模型的残差与林分年龄仍 然表现为显著的负相关关系 $(P<0.05$, 图1)。林分年 龄对萌生指标与地形因子回归模型残差的解释量 分别达到20\%-30\% (图1)。这说明在排除地形因素 的影响下, 萌生状况仍随林分年龄的增大而下降, 但林分年龄的解释力略有下降。

萌生个体数和萌生物种丰富度所占比例均随 林分年龄的增大而显著下降 $(P<0.05)$, 解释量分别 为 $45.2 \%$ 和 $36.4 \%$ (图2)。萌生物种主茎的平均胸径 随林分年龄的增大而显著增加 $\left(R^{2}=0.720, P<0.05\right.$, 图2)。

\section{3 讨论}

作为实生更新困难树种的一种补偿策略(何东 等, 2009), 萌生更新能够保证植物在受到干扰或环 境胁迫下快速占领原有空间资源, 坚守其固有生态 位, 维持其种群在群落中的稳定性(Bond \& Midgley, 2001)。萌生更新对受干扰后的森林植被尤其是次生 森林植被的恢复和重建具有重要作用。本研究发现 古田山常绿阔叶林内 $53.8 \%$ 的树种具有萌生特性, 且不同演替群落萌生能力存在差异, 而这种差异与 林分年龄和地形都密切相关。

\section{1 林分年龄对萌生能力的影响}

本研究发现古田山亚热带常绿润叶林群落萌 生能力随演替阶段的发展呈显著下降的趋势, 表明 萌生更新在演替早期对群落结构的维持具有重要 作用, 而随演替阶段的发展萌生更新的作用逐渐减 弱(间恩荣等, 2005; 苏建荣等, 2012)。这与国内外 气候湿润的热带、亚热带地区的研究结果一致 (Kammesheidt, 1998; 陈沐等, 2007; Shen et al, 


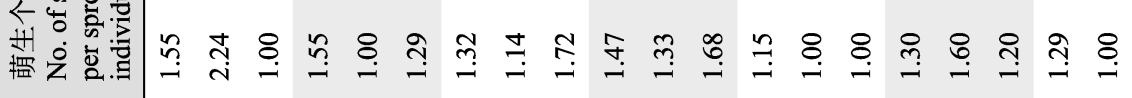

蛋



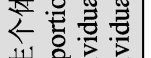

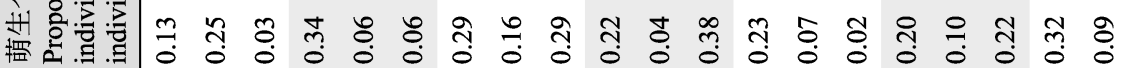
它

总言

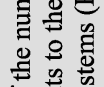

恻它

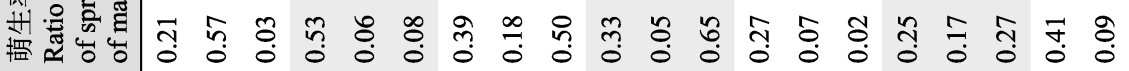

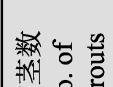

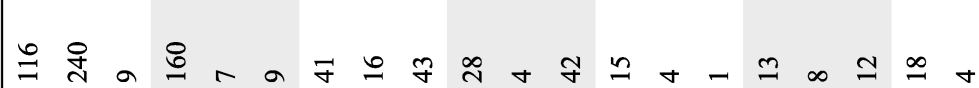

प

$\frac{1}{\sqrt{4}}$

㨫

䊀

产

๓

के

苛 莳

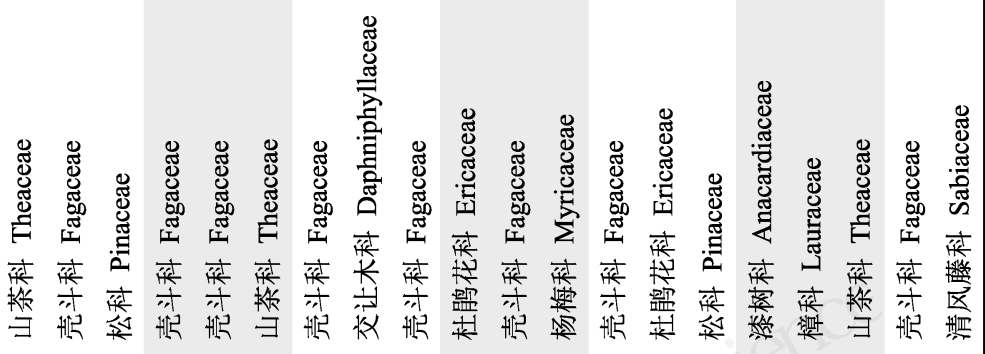


表2 萌生能力与林分年龄和地形因子的一元线性回归分析结果

Table 2 Relationships between sprouting ability and forest age and topographical factors

\begin{tabular}{|c|c|c|c|c|}
\hline $\begin{array}{l}\text { 萌生能力指标 } \\
\text { Sprouting ability index }\end{array}$ & $\begin{array}{l}\text { 变量 } \\
\text { Variables }\end{array}$ & $\begin{array}{l}\text { 回归斜率 } \\
\text { Coefficient }\end{array}$ & $\begin{array}{l}\text { 解释量 Explained } \\
\text { variation }\left(R^{2}\right)\end{array}$ & $P$ \\
\hline \multirow{4}{*}{$\begin{array}{l}\text { 萌生率 Ratio of the number of sprouts to the number } \\
\text { of main stems (RS) }\end{array}$} & 海拔 Elevation & -0.0007 & 0.258 & 0.0095 \\
\hline & 坡度 Slope & -0.0041 & 0.017 & 0.5328 \\
\hline & 坡向 Aspect & -0.0677 & 0.085 & 0.1567 \\
\hline & 林分年龄 Forest age & -0.0058 & 0.383 & 0.0010 \\
\hline \multirow{4}{*}{$\begin{array}{l}\text { 萌生个体比例 Proportion of sprouting individuals } \\
\text { among all individuals (PMSI) }\end{array}$} & 海拔 Elevation & -0.0003 & 0.262 & 0.0089 \\
\hline & 坡度 Slope & -0.0019 & 0.018 & 0.5193 \\
\hline & 坡向 Aspect & -0.0378 & 0.129 & 0.0781 \\
\hline & 林分年龄 Forest age & -0.0023 & 0.295 & 0.0050 \\
\hline \multirow{4}{*}{$\begin{array}{l}\text { 萌生个体平均萌茎数 Number of sprouts per } \\
\text { sprouting individual (NSMSI) }\end{array}$} & 海拔 Elevation & -0.0009 & 0.154 & 0.0522 \\
\hline & 坡度 Slope & -0.0065 & 0.015 & 0.5601 \\
\hline & 坡向 Aspect & -0.0697 & 0.031 & 0.3997 \\
\hline & 林分年龄 Forest age & -0.0091 & 0.322 & 0.0031 \\
\hline
\end{tabular}
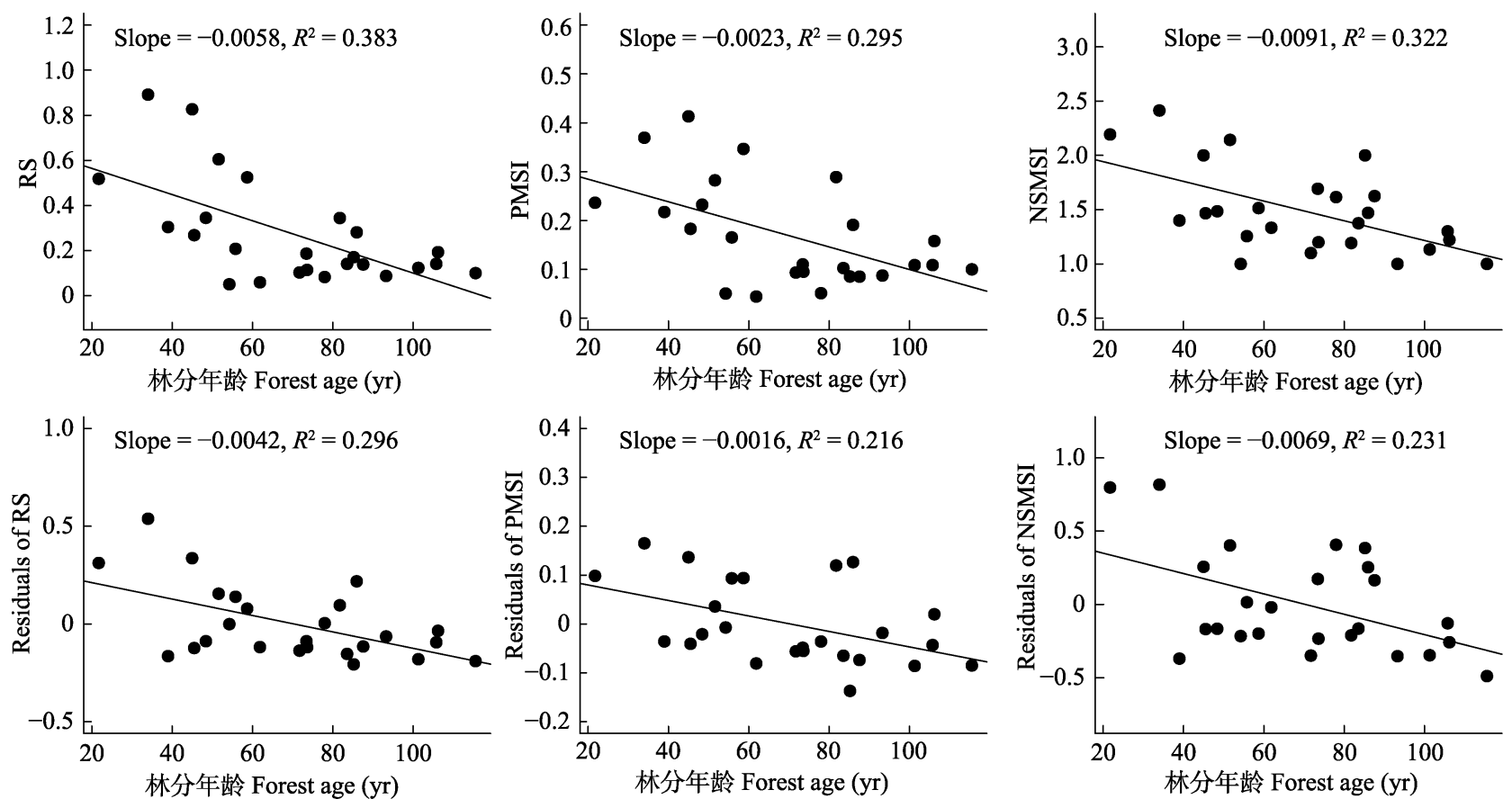

图1 群落萌生率(RS)、萌生个体比例(PMSI)、萌生个体平均萌茎数(NSMSI)及经地形因子拟合解释变异后各萌生能力指标 的剩余残差与林分年龄的关系。实线代表线性关系显著即 $\boldsymbol{P} \leq \mathbf{0 . 0 5}$ 。RS表示萌生率, 即样方内萌茎数与个体数之比; PMSI表 示萌生个体比例, 即样方内萌生个体数与所有个体数之比; NSMSI表示萌生个体平均萌茎数, 即样方内的萌茎数与萌生个体 数之比。

Fig. 1 Relationships between the ratio of the number of sprouts to the number of main stems (RS), the proportion of sprouting individuals among all individuals (PMSI) and the number of sprouts per sprouting individual (NSMSI) of communities and their residuals after being fitted models by topographical factors and forest age. Solid lines indicate significant relationship with $P$-value less than 0.05 .

2011)。不同演替阶段的物种组成与结构变化可能是 导致萌生作用变化的原因。首先, 随着林分年龄的 增长，尽管萌生物种的丰富度并未发生显著变化 (始终都在15种以上, 图2), 但是具体的物种类型发
生了变化。例如, 石栎、甜槠、木荷、青冈栎 (Cyclobalanopsis glauca)等萌生物种在不同演替阶 段均有分布，而马尾松、短柄枹栋、褐叶青冈 (Cyclobalanopsis stewardiana)、红枝柴(Meliosma 

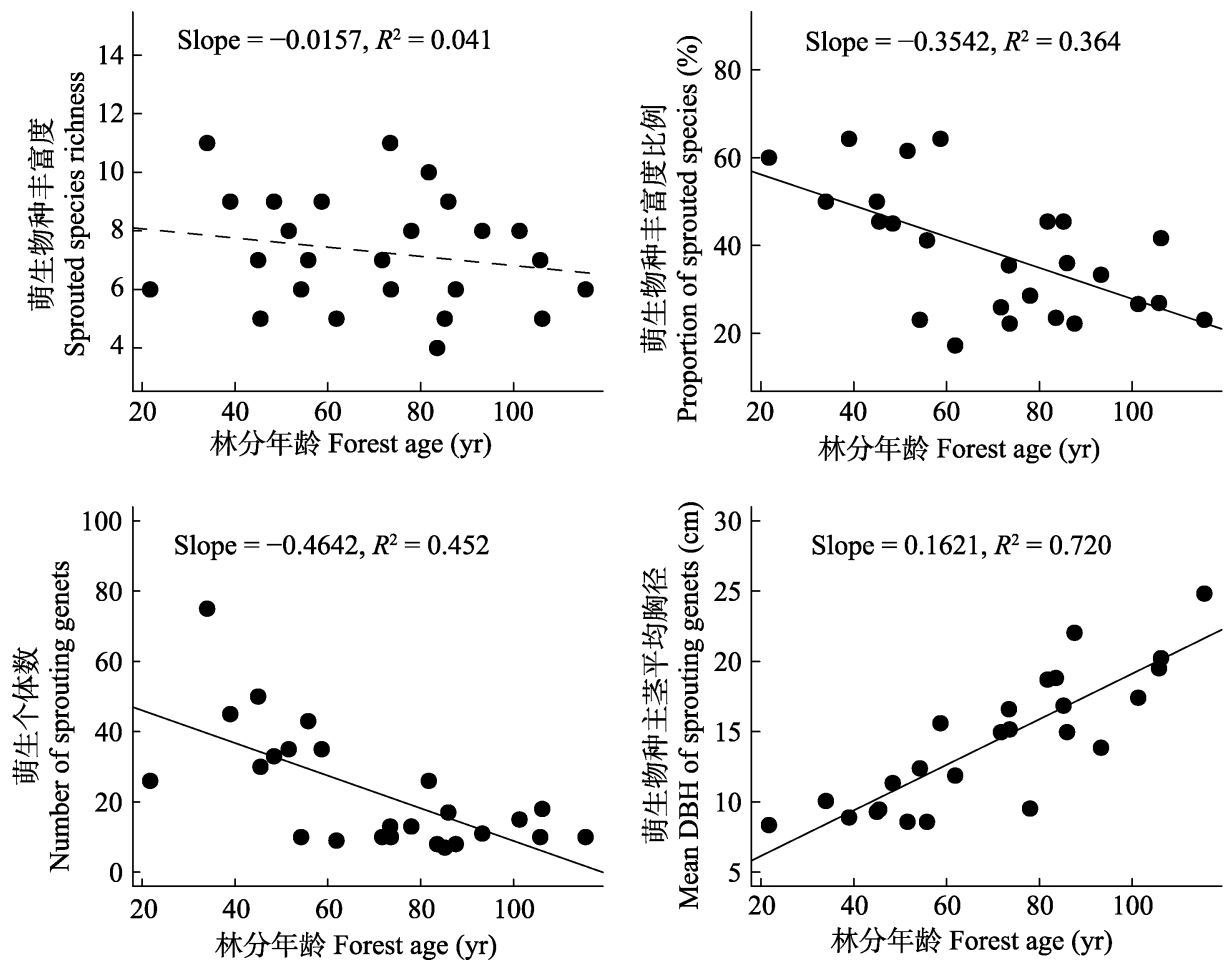

图2 萌生物种丰富度、萌生物种丰富度比例、萌生个体数及萌生物种主茎平均胸径与林分年龄的关系。实线代表线性关系 显著即 $P \leq 0.05$, 虚线代表线性关系不显著即 $P>0.05$ 。

Fig. 2 Relationships between sprouted species richness, proportion of sprouted species, number of sprouting genets, mean diameter at breast height $(\mathrm{DBH})$ of sprouting genets and forest age. Solid lines indicate significant relationship with $P$-value less than 0.05 , while dash lines indicate insignificant relationship with $P$-value greater than 0.05 .

oldhamii)等萌生物种在演替早期更常见, 鹿角杜鹃 (Rhododendron latoucheae)、毛花连荵茶(Camellia fraterna)、灰白蜡瓣花(Corylopsis glandulifera)、锥 栗(Castanea henryi)等萌生物种则较常出现在演替 后期。其次, 虽然群落内萌生物种的丰富度随林分 年龄增大无显著变化, 但群落内总物种丰富度随之 显著增大(Bruelheide et al, 2011), 萌生物种丰富度 所占的比例及萌生个体数均显著下降(图2), 这在一 定程度上可能降低了群落整体萌生现象的发生频 率及其萌生能力。这一现象与苏建荣等(2012)的研 究结果也较为一致, 他们发现云南普洱地区季风常 绿阔叶林干扰后不同恢复阶段(15年、30年及老龄林) 的群落内萌生物种及其个体多度所占比例(相当于 本研究的萌生个体比例PMSI)均随恢复时间延长呈 减少趋势, 萌生乔木物种丰富度无显著变化, 但其 比例呈减少趋势。

本研究还发现, 萌生物种主茎平均大小随林分 年龄增长而增大(图2), 即总体表现为萌生物种成年 个体的比例随林分年龄增大而增加。由于成年树通
常具有较强的抵御胁迫的能力, 并且将更多资源投 入到有性生殖, 从而使得许多成年树的萌生能力下 降甚至丧失(Kammesheidt, 1998; 刘常幸等, 2014), 进而可能引起演替后期群落水平萌生能力的下降。

另外, 土壤养分尤其是氮元素在有机质表层的 稳固性随着林龄的增大会增强，使得养分的可利用 性逐渐减少(Gower et al, 1996), 有可能限制了萌生 物种根、茎资源(如碳水化合物)的存储，从而使得萌 生受限(Shen et al, 2011), 引起群落水平萌生能力随 林分年龄增长而减弱。

\section{2 地形对萌生能力的影响}

地形常通过引起温度、降水(方精云等, 2004) 等因素的差异, 直接或间接地对植物的更新和分布 产生影响。本研究发现, 海拔对古田山常绿阔叶林 群落萌生能力影响较大, 并且在低海拔物种的萌生 能力更强。这可能是由于海拔与群落的受干扰程度 存在一定关联。例如Sandel和Svenning (2013)研究发 现，局地到全球尺度的毁林现象多集中于人们较易 到达的地形较平坦的低海拔地段。因此, 低海拔区 
域内较强的人为干扰会促进物种选择萌生更新方 式，以迅速占领原有的空间和生境资源 ${ }^{1}$ 。 Bellingham和Sparrow (2009)在新西兰的温带森林 中有类似发现，尽管高海拔样地内萌生发生的频率 高于低海拔地区, 但潜在的原因是靠近树线的高海 拔地区受环境胁迫较严重。刘海波等(2014)在湖南 八大公山25 ha亚热带山地常绿落叶混交样地的研 究发现, 高海拔位置土层较厚, 低海拔的山谷受雨 水冲刷作用大, 土壤生产力较低, 实生更新能力受 限制，因此在低海拔山谷生境内倾向于通过增强萌 生能力来维持种群的稳定。郭屹立等(2015)则在广 西弄岗喀斯特季节性雨林样地中发现萌生常发生 于土壤和水分条件较差的高海拔地段(山脊)。由此 可见，萌生现象与海拔没有适合于所有地区的一致 关系, 但不难发现海拔可以通过影响环境胁迫程度 或干扰状况来影响萌生更新。

此外, 我们发现坡向与萌生能力也有一定的关 系, 即朝南坡向的生境内物种的萌生能力更强。这 可能是由于坡向影响了辐射量等微气候条件, 从而 影响了萌生更新, 但还需要更多的研究来验证这种 推测。

总之, 古田山常绿阔叶林演替序列中, 萌生的 作用随着林分年龄的增加而逐渐下降，同时海拔和 坡向等地形因素也影响萌生状况。萌生能力随林分 年龄的动态与物种组成的变化(即萌生能力较强物 种的多度随演替而下降)和群落结构的变化(即大径 级个体随着演替逐渐增多)有关。本研究加深了我们 对萌生随演替序列变化的认识, 对亚热带常绿榈叶 林的恢复和保护提供了科学参考。

致谢: 感谢BEF-China项目组搭建的样方平台, 感 谢古田山自然保护区工作人员及当地居民提供的 支持和帮助。

\section{参考文献}

Bellingham PJ, Sparrow AD (2000) Resprouting as a life history strategy in woody plant communities. Oikos, 89, 409-416.

Bellingham PJ, Sparrow AD (2009) Multi-stemmed trees in montane rain forests: Their frequency and demography in

(1) 田否 (2015) 古田山5 ha样地木本根萌植物影响因子数值分析. 硕士 学位论文, 浙江师范大学, 浙江金华. relation to elevation, soil nutrients and disturbance. Journal of Ecology, 97, 472-483.

Bond WJ, Midgley JJ (2001) Ecology of sprouting in woody plants: The persistence niche. Trends in Ecology and Evolution, 16, 45-51.

Bond WJ, Midgley JJ (2003) The evolutionary ecology of sprouting in woody plants. International Journal of Plant Sciences, 164, S103-S114.

Bruelheide $\mathrm{H}$, Böhnke $\mathrm{M}$, Both $\mathrm{S}$, Fang $\mathrm{T}$, Assmann $\mathrm{T}$, Baruffol M, Bauhus J, Buscot F, Chen XY, Ding BY, Durka W, Erfmeier A, Fischer M, Geissler C, Guo DL, Guo LD, Hardtle W, He JS, Hector A, Krober W, Kuhn P, Lang AC, Nadrowski K, Pei KQ, Scherer-Lorenzen M, Shi XZ, Scholten T, Schuldt A, Trogisch S, von Oheimb G, Welk E, Wirth C, Wu YT, Yang XF, Zeng XQ, Zhang SR, Zhou HZ, Ma KP, Schmid B (2011) Community assembly during secondary forest succession in a Chinese subtropical forest. Ecological Monographs, 81, 25-41.

Chen M, Cao M, Lin LX (2007) Research advances in regeneration of woody plants by sprouting. Chinese Journal of Ecology, 26, 1114-1118. (in Chinese with English abstract) [陈沐，曹敏，林露湘 (2007) 木本植物萌生更新 研究进展. 生态学杂志, 26, 1114-1118.]

Clarke PJ, Lawes MJ, Midgley JJ (2010) Resprouting as a key functional trait in woody plants-challenges to developing new organizing principles. New Phytologist, 188, 651-654.

Del Tredici P (2001) Sprouting in temperate trees: A morphological and ecological review. Botanical Review, 67, 121-140.

Fang JY, Shen ZH, Cui HT (2004) Ecological characteristics of mountains and research issues of mountain ecology. Biodiversity Science, 12, 10-19. (in Chinese with English abstract) [方精云, 沈泽吴, 崔海亭 (2004) 试论山地的生 态特征及山地生态学的研究内容. 生物多样性, 12 , 10-19.]

Gower ST, Mcmurtrie RE, Murty D (1996) Aboveground net primary production decline with stand age: Potential causes. Trends in Ecology and Evolution, 11, 378-382.

Guo YL, Wang B, Xiang WS, Ding T, Lu SH, Wen SJ, Huang FZ, Li DX, Li XK (2015) Sprouting characteristics of tree species in $15-\mathrm{hm}^{2}$ plot of northern tropical karst seasonal rain forest in Nonggang, Guangxi, southern China. Chinese Journal of Ecology, 34, 955-961. (in Chinese with English abstract) [郭屹立, 王斌, 向悟生, 丁涛, 陆树华, 文淑均, 黄甫昭, 李冬兴, 李先琨 (2015) 弄岗北热带喀斯特季节 性雨林 $15 \mathrm{hm}^{2}$ 样地木本植物萌生特征. 生态学杂志, 34, 955-961.]

He D, Wei XZ, Li LF, Jiang MX, Yang JY, Yu J (2009) Population structure and dynamics of Cercidiphyllum japonicum in riparian zones of the Shennongjia Mountains region, central China. Chinese Journal of Plant Ecology, 33, 469-481. (in Chinese with English abstract) [何东, 魏新增, 李连发, 江明喜, 杨敬元, 喻杰 (2009) 神农架山地河岸 带连香树的种群结构与动态. 植物生态学报, 33, 
469-481.]

Hu ZH, Yu MJ (2006) Species diversity in four successional communities of evergreen broad-leaved forest in Gutian Mountain, Zhejiang Province. Chinese Journal of Ecology, 25, 603-606. (in Chinese with English abstract) [胡正华, 于明坚 (2006) 浙江古田山常绿阔叶林演替序列研究: 群落物种多样性. 生态学杂志, 25, 603-606.]

Kammesheidt L (1998) The role of tree sprouts in the restoration of stand structure and species diversity in tropical moist forest after slash-and-burn agriculture in Eastern Paraguay. Plant Ecology, 139, 155-165.

Lang AC, Hardtle W, Baruffol M, Böhnke M, Bruelheide H, Schmid B, von Wehrden H, von Oheimb G (2012) Mechanisms promoting tree species co-existence: Experimental evidence with saplings of subtropical forest ecosystems of China. Journal of Vegetation Science, 23, 837-846.

Liu CX, Jin Y, Yu JP, Chen SW, Tian L, Wang YQ, Chen JH (2014) Characteristics of root sprouting trees of Castanopsis eyrei and Schima superba communities in $1 \mathrm{hm}^{2}$ forest plot at Chawan, Gutianshan National Nature Reserve. Journal of Zhejiang University (Science Edition), 41, 573-582, 592. (in Chinese with English abstract) [刘常幸, 金毅, 余建平, 陈 声文, 田碞，王云泉，陈建华 (2014) 古田山茶湾样地甜 槠一木荷林根萌特征分析. 浙江大学学报(理学版), 41, 573-582, 592.]

Liu HB, Wang QG, Lu JM, Xu YZ, Lu ZJ, Qiao XJ, Bao DC, Guo YL, Meng HJ, Jiang MX (2014) Root-sprouting ability in an evergreen and deciduous broad-leaved mixed forest. Chinese Science Bulletin (Chinese Version), 59, 3491-3498. (in Chinese with English abstract) [刘海波, 王庆刚, 路俊 盟, 徐耀粘, 卢志军, 乔秀娟, 鲍大川, 郭屹立, 孟红杰, 江明喜 (2014) 八大公山常绿落叶阔叶混交林根萌能力. 科学通报, 59, 3491-3498.]

Nanami S, Kawaguchi H, Tateno R, Li CH, Katagiri S (2004) Sprouting traits and population structure of co-occurring Castanopsis species in an evergreen broad-leaved forest in southern China. Ecological Research, 19, 341-348.

Paula S, Cervelló CP, Pausas JG (2006) Fire as a germination cue: A review for the Mediterranean Basin. Forest Ecology and Management, 234, S176.

Paula S, Pausas JG (2006) Leaf traits and resprouting ability in the Mediterranean Basin. Functional Ecology, 20, 941-947.

Paula S, Arianoutsou M, Kazanis D, Tavsanoglu C, Lloret F, Buhk C, Ojeda F, Luna B, Moreno JM, Rodrigo A, Espelta JM, Palacio S, Fernández-Santos B, Fernandes PM, Pausas JG (2009) Fire-related traits for plant species of the Mediterranean Basin. Ecology, 90, 1420.

Pausas JG (2001) Resprouting vs. seeding: A Mediterranean perspective. Oikos, 94, 193-194.

R Core Team (2016) R: A Language and Environment for Statistical Computing. R Foundation for Statistical Computing, Vienna, Austria. https://www.R-project.org/.

Sandel B, Svenning JC (2013) Human impacts drive a global topographic signature in tree cover. Nature Communica- tions, 4, 1-7.

Shen YX, Yang GR, Huang J (2011) Comparison of tree sprouting in three regeneration stages of an evergreen broadleaved forest in a karst landscape, SW China. Acta Ecologica Sinica, 31, 126-132.

Su JR, Liu WD, Zhang ZJ, Li SF (2012) Sprouting characteristic in restoration ecosystems of monsoon evergreen broad-leaved forest in south-central of Yunnan Province. Acta Ecologica Sinica, 32, 805-814. (in Chinese with English abstract) [苏建荣, 刘万德, 张志钧, 李帅峰 (2012) 云南中南部季风常绿阔叶林恢复生态系统萌生特 征. 生态学报, 32, 805-814.]

Verdú M (2000) Ecological and evolutionary differences between Mediterranean seeders and resprouters. Journal of Vegetation Science, 11, 265-268.

Wang XH, Kent M, Fang XF (2007) Evergreen broad-leaved forest in Eastern China: Its ecology and conservation and the importance of resprouting in forest restoration. Forest Ecology and Management, 245, 76-87.

Yan ER, Wang XH, Shi JY, Wang XB, Wang LY (2005) Sprouting ecology of woody plants: A research review. Chinese Journal of Applied Ecology, 16, 2459-2464. (in Chinese with English abstract) [间恩荣, 王希华, 施家月, 王希波, 王良衍 (2005) 木本植物萌枝生态学研究进展. 应用生态学报, 16, 2459-2464.]

Ye D, Dong RR, Mi XC, Lu W, Zheng ZJ, Yu MJ, Ni J, Chen JH (2017) Characteristics and effects of sprouting on species diversity in a subtropical evergreen broad-leaved forest in Gutianshan, East China. Biodiversity Science, 25, 393-400. (in Chinese with English abstract) [叶铎, 董瑞瑞, 米湘成, 芦伟, 郑振杰, 于明坚, 倪健, 陈建华 (2017) 古田山常 绿阔叶林萌生特征及其与群落物种多样性的关系. 生物 多样性, 25, 393-400.]

Ye D, Qian HY, Wang LY, Jin FM, Ni J, Chen SW, Song YF, Chen JH (2018) Sprouting characteristics of woody species in a subtropical evergreen broad-leaved forest in Gutianshan of Qianjiangyuan National Park, East China. Acta Ecologica Sinica, 38, 3562-3568. (in Chinese with English abstract) [叶铎, 钱海源, 王璐瑶, 金芳梅, 倪健, 陈声文, 宋云峰, 陈建华 (2018) 钱江源国家公园古田山常绿阔叶林木本 植物的萌生更新特征. 生态学报, 38, 3562-3568.]

Ye J, Hao ZQ, Wang XG, Bai XJ, Xing DL, Yuan ZQ (2014) Local-scale drivers of multi-stemmed tree formation in Acer, in a temperate forest of Northeast China. Chinese Science Bulletin, 59, 320-325.

Zhou SX, Jiang MX, Bao DC, Tao M, Huang HD (2011) Population structure and regenerative characteristics of major tree species of rare plant community in Houhe Nature Reserve. Guihaia, 31, 209-216. (in Chinese with English abstract) [周赛霞, 江明喜, 鲍大川, 陶敏, 黄汉东 (2011) 后河自然保护区珍稀植物群落结构及更新特性. 广西植 物, 31, 209-216.]

(责任编委: 米湘成 责任编辑: 问文杰) 